\title{
La guerra de Vietnam en la poesía española
}

\section{The Vietnam War in Spanish Poetry}

\author{
Julio Neira \\ UNED \\ jneira@flog.uned.es \\ ORCID iD: https://orcid.org/0000-0001-9306-2515
}

\section{RESUMEN}

A mediados de la década de 1960, en pleno debate dentro de la lírica española entre el mantenimiento del compromiso político y social de la poesía y la búsqueda de nuevas poéticas por parte de una nueva promoción de autores nacidos después de la guerra civil, un tema concita la unanimidad de todo el ámbito poético: la guerra de Vietnam. Poetas de todas las edades, ideologías, estéticas y lenguas peninsulares se implicaron en la denuncia de las atrocidades de aquella guerra imperialista que conmocionó a todas las sociedades occidentales y muy especialmente la española, que concibió la protesta como una forma más de lucha contra la dictadura del general Franco, firmemente apoyada por los Estados Unidos de América. En el presente artículo se reúne un abundante corpus de poemas que abordaron esa temática.

Palabras Clave: guerra de Vietnam; poetas del medio siglo; novísimos; generación de 1968; denuncia anti-imperialista; poesía política; censura; lucha anti-franquista.

\begin{abstract}
The Spanish poetry of the 1960s focuses on a fundamental issue: the maintenance of political and social commitment and the search for new poetics forms through a new promotion of authors, who were born after the Civil War. Nevertheless, there is a common topic for all of them: the Vietnam War. Poets of differents ages, ideologies and aesthetics, who write in the various peninsular languages, were implicated in the denunciation of the atrocities commited during that imperialist war. The Vietnam War shocked all Western societies and especially the Spanish country, as the Spanish population conceived the protest as another form of struggle against the dictatorship of General Franco, supported by the United States of America. This paper collects a significant number of poems dealing with this topic.
\end{abstract}

Key words: Vietnam War; Generation of 1950; «Novísimos»; Generation of 1968; Anti-imperialist movement; Political poetry; Censorship, Anti-Francoist poetry. 
En la segunda mitad de la década de 1960 el debate en la poesía española se centró en el litigio entre poéticas que propugnaban el mantenimiento del compromiso político y social, expresado a través de un realismo experiencial de mayor o menor intensidad (Gabriel Celaya, Blas de Otero, Ángel González, Caballero Bonald, Carlos Barral, José Agustín Goytisolo, Jaime Gil de Biedma), y las que defendieron la obsolescencia de esa retórica militante y la necesidad de buscar nuevas fórmulas, que centraran la radical ruptura con la mezquina realidad del franquismo en la experiencia del lenguaje y de la cultura (Lanz 2008, 2009, 2011; Iravedra y Sánchez Torre 2010; García 2012). En buena medida, la polémica tenía un marcado componente generacional, pues quienes cultivaban una poesía más o menos vinculada a la lucha anti-franquista habían vivido la guerra civil, mientras quienes buscaban nuevos caminos poéticos habían nacido a partir de 1939, y conocieron solo la posguerra. La crítica ha venido denominando a estos autores novísimos, venecianos, poetas del lenguaje, generación del 70 o, a mi parecer más propiamente, generación de 1968 (Lanz 2011).

Como en toda simplificación didascálica, en estos marbetes se encuadra a poetas tan diversos como Manuel Vázquez Montalbán, José Miguel Ullán, Pere Gimferrer, Antonio Martínez Sarrión, José Ma Álvarez, Leopoldo María Panero, José Infante, el grupo Claraboya (Agustín Delgado, Luis Mateo Díez, José Antonio Llamas) o Cristina Peri Rossi. Si bien es cierto que tampoco en el grupo de los llamados del medio siglo hubo uniformidad, sino una saludable diversidad (Payeras Grau, 2016). Y, sin embargo, en ese periodo entre 1966 (Premio Nacional de Poesía de Gimferrer con Arde el mar) y 1970 (antología de Castellet Nueve novísimos poetas españoles) en que se fragua un cambio de rumbo en el canon de la poesía española, sí hubo un asunto que concitó inusual unanimidad: la protesta contra la guerra de Vietnam.

En las páginas que siguen encontraremos muchos otros ejemplos de ese rechazo en la obra de poetas de edades, ideologías y estéticas muy diferentes. Veremos casos de autores ya muy mayores, como León Felipe, que superaba los ochenta años y moriría al poco; de los nacidos en la última década del siglo XIX y en la primera del XX (Jorge Guillén, Gerardo Diego, Vicente Aleixandre, Ángela Figuera, Rafael Alberti); de la siguiente, como Salvador Espriu, Juan Bernier, Celso Emilio Ferreiro, Blas de Otero y Leopoldo de Luis; de los llamados poetas del 50, como José Manuel Caballero Bonald, Ángel González, Alfonso Sastre, José Agustín Goytisolo, Carlos Álvarez, Julio Alfredo Egea, Gloria Fuertes, Gabriel Ferrater, Carlos de la Rica y José Ángel Valente; de casi todos los citados del grupo del 68; y de otros más jóvenes, como Francisca Aguirre, Félix Grande o Marcos Ricardo Barnatán. En suma, el motivo interesó y ocupó al conjunto de poetas, hombres y mujeres, españoles. La abundancia de ejemplos demuestra que no se trató de una marca generacional, sino de un signo de la época.

La guerra de Vietnam tuvo una larga historia que conviene ahora resumir. Empezó allí donde acababa la de Indochina, que perdió Francia, potencia coloni- 
zadora de toda la península. El tratado de Ginebra de 1954 estableció la creación de Laos y Camboya como estados independientes y la división en dos de Vietnam por el paralelo 17: al Norte la República Democrática de Vietnam, donde se reagruparon las fuerzas independentistas y comunistas del Viet Minh, y al Sur el Imperio de Annan, bajo el emperador Bao Dai y la influencia occidental. En 1955 un golpe de estado del general Ngo Dinh Diem con apoyo de la CIA propició la creación de la República de Vietnam del Sur e impuso un régimen dictatorial que impidió la celebración del referéndum de unificación previsto para 1958 ante el temor al previsible triunfo del «sí». Las guerrillas comunistas que venían operando en el Sur se agruparon en el Frente de Liberación Nacional de Vietnam, luego conocido como Viet Cong, y comenzaron su guerra contra la dictadura en 1959.

Desde 1950, como consecuencia de la guerra fría con la Unión Soviética, los Estados Unidos venían combatiendo la expansión comunista en la zona con medios logísticos y económicos, así como con asesores militares del ejército regular survietnamita, pero fue en la década siguiente cuando el desarrollo de las operaciones bélicas, claramente desastroso para sus aliados del Sur, llevó al presidente Lyndon B. Johnson a implicarse en la guerra con envío masivo de tropas al terreno y una política de bombardeos devastadores del territorio del Norte. Pretextando un incidente naval en el golfo de Tonkin en agosto de 1964, Johnson consiguió la autorización del Congreso para el envío de marines y la actuación militar fuera de sus bases. A mediados de 1965, aun sin declararla formalmente, Estados Unidos había convertido la de Vietnam en una guerra propia: la más larga de las que mantuvo en el siglo $\mathrm{XX}$ y la que le produjo una amarga derrota que conmocionó su sociedad durante décadas.

El uso de armas químicas con agentes herbicidas que arrasaban las selvas donde operaban los norvietnamitas, el napalm que devastaban poblaciones enteras, matanzas de civiles como la de My Lai, donde las tropas norteamericanas arrasaron una aldea, violaron a mujeres y niñas y asesinaron a cientos de personas en marzo de 1968, la corrupción del régimen dictatorial que sustentaban-Diem fue asesinado en un golpe militar a cargo de Nguyen Van Thieu en 1963- y la ausencia de razones fundadas para una intervención tan desproporcionada, generaron la repulsa de los sectores progresistas de las sociedades occidentales, y la juventud norteamericana se puso abiertamente en contra, tomando la bandera del pacifismo como elemento nuclear del movimiento hippie que floreció en ese mismo tiempo.

A partir de 1968 el curso de la guerra cambió de signo. Pese a que consiguieron derrotar a las fuerzas del Viet Cong en su gran ofensiva del Tet, la moral de las tropas decayó de una manera alarmante al comprobar que eran incapaces de vencer a unas fuerzas peor dotadas y preparadas, pero decididas a luchar hasta el fin. La idea de que era una guerra imposible de ganar acabó instalándose en la Administración norteamericana y Lyndon Johnson destituyó al general en jefe William Westmoreland y ordenó planes para la retirada. En enero de 1969 asumió la presidencia Richard Nixon, quien inició el proceso de vietnamización del conflicto, al tiempo que Henry Kissinger iniciaba conver- 
saciones secretas en París para buscar un final negociado, que se alcanzó finalmente en los Acuerdos de Paz de París el 27 de enero de 1973, que permitieron salir de la guerra a Estados Unidos, aunque para Vietnam no serían sino una pausa. La guerra acabó tres años después, el 30 de abril de 1976, con la toma de Saigón por las tropas comunistas, la simbólica y atropellada evacuación de la embajada norteamericana y la rendición incondicional del gobierno del Sur, que dio paso a la unificación del territorio en la actual República de Vietnam.

En ese contexto de guerra fría resultante de la II Guerra Mundial, que duraría hasta el desmoronamiento del bloque comunista en 1991, al apoyo norteamericano a Vietnam del Sur se contrapuso el de la Unión Soviética y la China maoísta al del Norte. Y la batalla ideológica y propagandística se extendió a todo el mundo. No extraña por ello que poetas de reconocida militancia comunista alzasen su pluma contra la intervención norteamericana, como Rafael Alberti -galardonado por los soviéticos con el Premio Lenin de la Paz en 1965- que escribió el conocido soneto «Vietnam», incluido en su libro Roma peligro para caminantes (1968). En realidad, el poeta gaditano tenía bien acreditada la fama de poeta antiimperialista. En 1935 había denunciado la injerencia norteamericana en Centroamérica en su libro 13 bandas y 48 estrellas. Poema del Mar Caribe, resultado de su viaje de agitación política realizado aquel año con María Teresa León. Denunciaba en él la injerencia militar y la económica, como muestra el poema «Wall Street» sobre el abuso de las compañías multinacionales en la región. Y en 1953, año en que visitó la Unión Soviética y varios países de la Europa del Este, había escrito contra el Acuerdo hispano-norteamericano y la instalación de la base de Rota en su querida bahía gaditana poemas como «A Cádiz, base extranjera», «Del soldado español al soldado yanqui», «Rota oriental, spain» y «Sonsonete de la coca-cola», que reuniría en el libro Signos del día, publicado en Poesías completas (1961).

El soneto «Vietnam», escrito en $1965^{1}$, denuncia la invasión y reclama el cese el fuego y el establecimiento de la paz en un lenguaje muy directo. A diferencia de Blas de Otero, fuera de España Alberti disponía de la palabra, con la que reclamaba la paz:

Lo grito fuerte desde Roma: ¡Afuera!

afuera esos fusiles y cañones,

esos cohetes, esos aviones,

esa bandera extraña, esa bandera.

Afuera el que en la paz tan sólo espera

invadir por la paz otras naciones

y planta por la paz sus pabellones

y pide por la paz la tierra entera.

\footnotetext{
${ }^{1}$ Fue publicado por primera vez en Alberti (1966).
} 
Triste paz tan traída y tan llevada, triste paloma tan apuñalada que se puede morir tan de paloma.

Pido la única paz, la verdadera, la paz de un solo rostro, antes que muera.

¡Pido la paz! Lo grito desde Roma (Alberti 1988, 67).

No es el único poema de Alberti sobre el asunto, pues en Disprezzo e meraviglia, una antología bilingüe editada en Roma (1972), incluyó un poema así llamado, «Desprecio y maravilla», escrito también en $1968^{2}$, coincidiendo con la ofensiva del Tet, dedicado «A todos los norteamericanos que estén contra la guerra de Vietnam». En él, los términos del oxímoron se refieren a los dos bandos: el negativo para las tropas norteamericanas:
Desprecio para ti, vergüenza, escupo, escupo
contra ti, a tantos miles de kilómetros, yanki invasor, enanos coca-cola, vacíos satisfechos, millonarios piojos, sangrientos impotentes.
$[\ldots]$
Desprecio de la lengua que a diario amenaza
pulverizar la vida con las armas atómicas.
Desprecio de la triste victoria conseguida
al precio de la súbita muerte total de todo.

Y el positivo para los esforzados combatientes vietnamitas que luchan por su independencia:
Maravilla, pequeño guerrillero que sales
de la sombra a la luz y en la luz te agigantas.
Maravilla sentirte en la noche que escucho
no darle tregua al sueño del orgullo enemigo.
$[\ldots]$
Maravilla saber que presencié los años
en los que existió un pueblo que fue asombro del mundo.
Maravilla escribir a ese pueblo un poema
y cien y mil y nunca acabar su alabanza.

El lenguaje de estos alejandrinos blancos conjuga denuesto e hipérbole a partes iguales, con la soltura que es habitual en la poesía política del gaditano, que no ocultaba su decidido alineamiento con la lucha del Viet Cong.

Pero si en Alberti era de esperar ese pronunciamiento poético, sorprende que también lo hiciera quien tal vez fuese su amigo ideológicamente más dis-

\footnotetext{
2 José María Balcells documentó una versión mecanografiada fechada en Antibes, febrero 1968 (Alberti 2004, 1016-1017). Seguramente fue escrito durante una de las visitas que el poeta hizo a Pablo Picasso.
} 
tante: Gerardo Diego (Neira 2001). En 1966 el poeta santanderino incluyó en su libro Odas morales, publicado por Ángel Caffarena en Málaga, una «Oda a los vietnameses» que responde no a una militancia política, que él nunca tuvo, sino a un imperativo ético o moral que siempre sintió. En el poema, compuesto en liras rimadas, Diego denuncia la desproporción del enfrentamiento («La ley de la rapiña / sigue imperando en cerco tenebroso. / Innoble rebatiña: dragón, águila y oso / tras cordero interpuesto entablan coso.»); y se lamenta por la destrucción de un espacio natural tan arcádico, similar al que conoció durante su viaje a Filipinas en 1935:

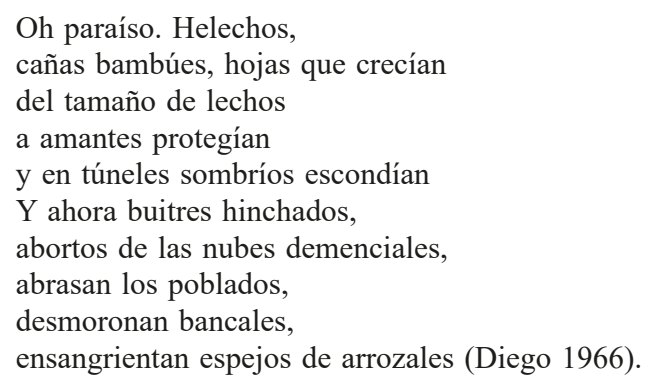

El horror de la guerra afectaba no solo a quienes tenían convicciones políticas. En su estudio sobre la poesía de Aníbal Núñez afirma Rosamna Pardellas Velay $(2009$, 118): «La minoría culta, de formación universitaria, a la que pertenecen los jóvenes poetas, está, no obstante, bien informada sobre el desarrollo de la Guerra de Vietnam y las manifestaciones de protesta contra ella que se producen en los EE.UU.». Pero pienso que no solo ese estrato social estaba al tanto, sino capas mucho más amplias de la población, pues aquella guerra fue la primera televisada. A través de su corresponsalía en Nueva York, desempeñada por Jesús Hermida, Televisión Española dio en sus informativos cumplida noticia de los avatares de la guerra y las manifestaciones contrarias en las calles. Y si bien las cadenas que cubrían sobre el terreno los acontecimientos eran estadounidenses, la crudeza de las imágenes, los campos devastados, la población civil obligada a abandonar sus pueblos arrasados, el efecto del napalm, la resistencia de los guerrilleros comunistas, llegaban puntualmente a los hogares españoles, que ya entonces disponían mayoritariamente de televisor. Lo mismo ocurría con la información radiofónica y periodística, entonces controlada por el aparato del Régimen, que nunca pudo erradicar del todo su antiamericanismo original; de manera que la guerra de Vietnam, pese a su lejanía geográfica, fue asunto cotidiano para los españoles. A ello se refiere Gloria Fuertes en su poema «Poeta de guardia»:

... ¡Otra noche más! ¡Qué aburrimiento!

¡Si al menos alguien llamase llamara o llamaría!

$[\ldots]$ 
O que la radio dijera finamente:

«iLa guerra del Vietnam ha terminado!»

(Fuertes 1968, 9).

$\mathrm{Y}$ en «Extranjero-noticias»:

Yo, la tan pacífica, estoy impacífica, impaciente.

Yo, la tan tranquila, estoy de sostén de fuerza

de camisa, de Vietnamita -norte o sur-.

¡Ese Cristo del siglo XX

muerto por nosotros!

-no amén-. (Ibíd., 93).

Y José Agustín Goytisolo en su «Piazza Sant’Alessandro 6»:

Querida Carmen: hoy

no me importa que digan los periódicos

que prosigue la huelga de estudiantes

que ataca el Viet-Cong

(Goytisolo 2009, 184)

No extraña, entonces, que al escribir su diálogo sobre la guerra Vicente Aleixandre pensase en la del Vietnam, aunque no la mencione explícitamente al publicarlo en libro, como demuestran sus referencias a la selva y a las atrocidades cometidas en las aldeas por las armas químicas:

¡Cuan lejos ya! Aquí en la selva acato

la única luz y vivo...

[...] ¡Qué pájaros fantasmas, qué chirridos

fantasmas!...

Solo quedé. Arrasada está la aldea.

Ah, el miserable

conquistador pasó. Metralla y, más, veneno

vi en la mirada horrible- $\mathrm{Y}$ eran jóvenes.

(Aleixandre 1974, 11-12) ${ }^{3}$.

Al enviar el texto del poema a Angelina Gatell para la antología que esta preparaba, y a la que me referiré luego, el 1 de abril de 1968 le advierte: «No solo está escrito para Vietnam, pero sí para las guerras imperialistas de las que Vietnam es hoy el más sangrante ejemplo» (Neira 2016, 37); y el 27 de julio

${ }^{3}$ El poema, «Sonido de la guerra» se publicó con el título «Después de la guerra» en 1972, Valencia, Fomento de Cultura Ediciones. Hontanar suplementos. 
siguiente le da el título de «Guerra (Sombra del Vietnam)». Con ello la palabra Vietnam va en él, como ustedes deseaban» (ibíd., 38).

Más lógico resulta, si cabe, que Jorge Guillén se hiciera eco en su poesía de la guerra de Vietnam, pues por esos años seguía siendo docente en Cambridge, Massachusetts, y vivía de cerca el impacto de la guerra y las inquietudes de la juventud norteamericana. La segunda sección de su libro $Y$ otros poemas (1973), fechado entre 1966 y 1972, titulada «Sátiras» se inicia con cuatro textos que se refieren indudablemente a la guerra vietnamita. El primero es un crudo juicio sobre la barbarie de los bombardeos:

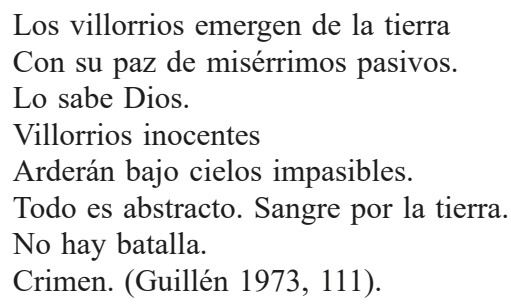

El segundo, «No tengáis miedo. No es el fin del mundo», ironiza sobre la capacidad del ser humano de crear bombas aún más mortíferas e insiste en considerar las muertes producidas en el ámbito de la criminalidad: «No existe nunca Régimen / Sin sus asesinatos aplaudidos» (ibíd.). El tercero, «En la televisión», denuncia la trivialización del horror:

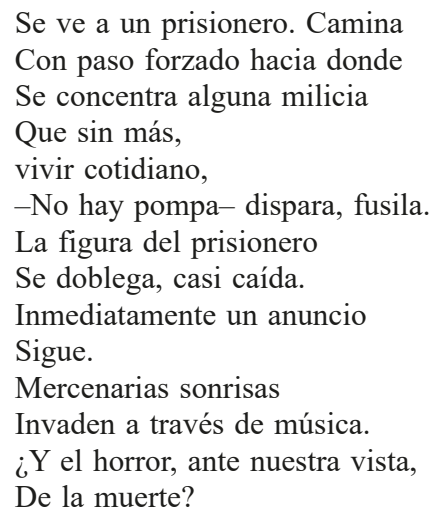

Por fin, en el cuarto comenta la existencia de un informe militar que afirma la posibilidad de que sea «destruida cualquier nación como sociedad visible», que atribuye en el lema al General E. G. W., y concluye:

Aquí no hay magia.

Es nada más Historia. 
Mil novecientos ya sesenta y ocho.

(Ibíd., 113).

Se trata del Guillén comprometido con la realidad de su tiempo posterior a la II Guerra Mundial, tan lejano de aquella imagen de poeta puro del primer Cántico (1928) que nos transmiten manuales simplificadores; quien en la sátira 39 vuelve a denunciar la sevicia de la guerra en sus imágenes cotidianas y la posición de EE.UU.:

Niños desnudos por las carreteras

Huyen enloquecidos. las hogueras

Bajo las bombas arden al servicio

Del hombre occidental: negocio, vicio.

«Ellos mueren. Yo, Jefe, mientras, hablo».

¿Se destruye también el blanco diablo? (Ibíd., 133).

Buen conocedor también de la sociedad norteamericana por haber vivido en ella largos años fue León Felipe (1884-1968), cuya trayectoria antiimperialista era igualmente bien conocida. Obra de su último año de vida fue el poema elegíaco «El gran relincho», dedicado «Al Che Guevara, mi gran amigo», el icono revolucionario por antonomasia de esa década y de las siguientes. Ernesto Guevara, había fallecido en Bolivia en octubre de 1967 en su intento de exportar la revolución a todo el Tercer Mundo, implantando muchos Vietnam sublevados contra el capitalismo norteamericano en África y Latinoamérica. Despertaba la simpatía de la izquierda europea y americana y fueron numerosos los poetas españoles que le dedicaron textos encomiásticos en un volumen que abrió este poema de León Felipe (AA.VV. 1969) . En él la referencia a Vietnam era obligada. El relincho es la exigencia de «iJusti-i-i-i-i-cia!»:

Venid. Vamos a relinchar ahora,

ahora mismo todos juntos

desde el capitolio de Washington...

fuerte, fuerte, FUERTE...

hasta que el relincho llegue a Vietnam

y lo oigan todos los vietnamitas

y a Cuba también

${ }^{4}$ De Poemas al Che hubo reproducción facsimilar en Barcelona, Los libros de la Frontera José Batlló, 1976 y 1978. Entre los poetas españoles participantes en esta ofrenda lírica destacan Vicente Aleixandre, Victoriano Crémer, Gabriel Celaya, Carlos Bousoño, J. A. Goytisolo, José A. Valente, Rafael Ballesteros, Carlos Sahagún, Manuel Vázquez Montalbán, Antonio Carvajal y José-Miguel Ullán, Celso Emilio Ferreiro, Manuel de Pedrolo y Gabriel Aresti. Buena parte de ellos habían sido dados a conocer en el número 4 de la revista Si la píldora bien supiera no la doraran tanto por defuera, dirigida por Batlló, diciembre de 1968-enero de 1969, que publicó también poemas de Ho Chi Ming, el líder de Vietnam del Norte. 


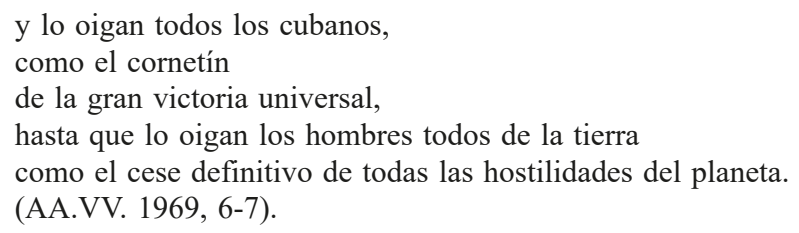

Antes incluso que Gerardo Diego, Blas de Otero había incorporado Vietnam a las preocupaciones de su poesía, probablemente más y durante más tiempo que ningún otro poeta español. Era sobradamente conocida su militancia en el Partido Comunista de España, que sufragó los gastos de su exilio voluntario en La Habana entre 1964 y 1968. Cuba era aliada de Vietnam del Norte, pues compartían enemigo común, y allí las vicisitudes de la guerra eran noticia de primer nivel, más incluso que en España, y la causa de la unidad territorial e independencia de Vietnam fue asumida como propia por los medios oficiales cubanos. El poeta bilbaíno demostraría en sus textos haberla interiorizado como algo personal, según evidencia la publicación reciente de su obra inédita. La datación precisa de los textos permite seguir con bastante detalle la evolución del topos. La preocupación de Blas de Otero por Vietnam venía de tiempo atrás y llegaría a ser obsesiva. En Poesía e historia, inédito como libro autónomo hasta su inclusión en la Obra completa (Otero 2013), encontramos referencias en los poemas «Historia» (1964-1966), «Crear lo que no vimos» (1967) y «Una especie de» (febrero de 1968), escritos en Cuba.

De julio de 1966 data la escritura de los poemas «Zaguán», de Historias fingidas y verdaderas, "Vietnam hasta cuándo» (ibíd., 658) y «Las nubes», también fechado en 1966, en el que un vagabundo contempla las nubes tumbado en un ribazo y observa: "Una nube morada fue dilatándose de sur a norte, estrechando y serpenteando sus riberas. Acaso adquiriendo una fugaz semejanza con Vietnam» (ibíd., 687). En Poesía e historia encontramos textos de 1967, como «Solidaria Isla», que acaba con el verso: «Así Vietnam ardiendo de Norte a Sur, iluminando el rostro de los guerrilleros» (ibíd., 665); y otros de 1968, como «Hacia las Azores», que da cuenta de su llegada a Madrid en abril y de su conversación con el taxista que le recoge en el aeropuerto: «¿Cómo dice? Sí, eso del Vietnam es una salvajada, en eso estamos todos de acuerdo. Luz amarilla. (No durará mucho)» (ibíd., 672).

Ya en Madrid, tras una grave enfermedad que le lleva al quirófano y pone en riesgo su vida, siente íntimamente la angustia por aquella lejana guerra que sufre. El 8 de junio de 1968 se fecha «Cuando yo me estoy muriendo», donde evoca sus felices días habaneros: «y estoy leyendo unos poemas en la Secundaria Básica de Pinar del Río, / y ofrezco mi vida por Vietnam y esta tarde pasearé por el Barrio Blanco» (ibíd., 722). Un mes más tarde, el 12 de julio, escribe el poema «La eficacia y el aire», donde leemos:

La mañana purísima, el escarabajo de oro. 


\begin{abstract}
Ahora en Vietnam.
Ahora en Vietnam estalla la primera bomba junto a una escuela de bambú, y esa muchacha que lleva un cántaro a la cabeza lo deposita rauda en el suelo y embraza su fusil-ametrallador.

Y yo estoy envuelto por el aire de Madrid.

[...]

Ahora en Vietnam un paracaídas blanco desciende sobre los ojos indefensos de los niños,

y yo conozco la proximidad de mi muerte tanto como la de la victoria del pueblo y simplemente escribo porque comprendo la eficacia de otras formas de lucha que, inexorable y pausadamente, conducen al mismo fin. (Ibíd., 732-733)
\end{abstract}

Del día 6 de agosto es «Cantar de amigo», donde se reiteran la intuición de la muerte próxima y la empatía por Vietnam:

¿Dónde está Blas de Otero? Está dentro del sueño, con los ojos abiertos.

[...]

¿Dónde está Blas de Otero? Está en el quirófano con los ojos abiertos.

¿Dónde está Blas de Otero? Está en Vietnam del Sur, invisible entre los guerrilleros.

¿Dónde está Blas de Otero? Está echado en su lecho, con los ojos abiertos.

¿Dónde está Blas de Otero? Está muerto, con los ojos abiertos (Ibíd., 766-767).

Fueron muchos los que entre 1966 y 1968 sintieron el imperativo ético de poner su pluma al servicio de la causa de la paz, denunciando la situación de Vietnam. Félix Grande (1937-2014) había incluido referencias en poemas de su libro Música amenazada, galardonado con el Premio Guipúzcoa de 1965, aunque publicado en 1966. En «Circo pobre» narra una visita al estudio del pintor Enrique Gran y su conversación, en la que sale a relucir su compartida devoción por César Vallejo y la guerra: «Vietnam, dice. El vocablo / se le despega de la boca como un parche poroso. / Miro su rostro, innumerable de admiración...» (Grande 2011, 145). El asunto reaparece en poemas de Blanco Spirituals -libro escrito en 1966 y premiado en 1967 con el Casa de las Américas de Cuba, cuyo gobierno era tan solidario con los norvietnamitas- que tienen la prensa como fuente habitual. En «Recuerdo de infancia» se refiere a la continua pérdida de vidas:

hoy el periódico traía sangre lo mismo que otros días

acaso unos cuantos estertores más que de hábito

pero cómo saberlo hay países que no especifican

por ejemplo el departamento de estado no da cifras de sus bajas

únicamente les agrega apellidos

bajas insignificantes, bajas ligeras, bajas moderadas (Ibíd., 179).

En el diario del 1 de noviembre de 1966 encuentra el inicio del poema «Telas graciosas de colores alegres»: 
Según el ABC de hoy Johnson ha motivado un nuevo agonizante en la capital de Malasia (se ve un caído junto a la bota de un policía y la bandera norteamericana en un ángulo de la derecha) (Ibíd., 196).

En «Sonata para duda y sordina» se rebela ante la insensibilidad generalizada con que se recibían las noticias y las imágenes procedentes de Vietnam en periódicos y noticiarios cinematográficos:

si la suma del sufrimiento no nos arrebata el descanso y los cadáveres que se enfrían a miles de kms.

no nos producen una úlcera de duodeno o un forúnculo será porque el amor universal no pasa de ser una idea (Ibíd., 222).

«Mejor para mí» lleva un lema tomado del madrileño diario Pueblo el 26 de enero de 1966, que dice: «En los años setenta U.S.A. tendrá misiles suficientes para arrasar a Rusia y a la China comunista», y contrasta su vida cotidiana con la situación internacional:

mientras que los wallstreetianos requiebran al pentágono y envían gigantescos adolescentes y cajas de chicle al Vietnam y la graciosa majestad de Johnson otrora sólo vicepresidente inaugura una ley que prohíbe casarse por terror (Ibíd., 229).

Al poco de instalarse en España, el argentino de origen sefardí Marcos Ricardo Barnatán (1946) escribe «Indochina 1966», incluido en su libro Los pasos perdidos (1965-1967) (Barbatán 1984, 39). Y ese mismo año José-Miguel Ullán (1944-2009) publicó en la revista Claraboya el poema con que suele ejemplificarse el tratamiento de este tema por los poetas entonces emergentes: «Lamentaciones de una muchacha yanqui a eso de la medianoche» (Ullán 1966, 16):

A Vietnam se fue mi amor.

Ye, ye, ye...

A Vietnam se fue mi amor.

Luchando lleva ya un año.

Ye, ye, ye...

Y solita quedé yo.

Regresa a bailar conmigo,

haz una tregua de amor.

Regresa en paracaídas,

mátame de corazón.

Luchando lleva otro año.

¡Ay del Pentágono! 
Y no regresa mi amor.

Llorando paso los días.

¡Ay del Pentágono!

Llorando, mi amor, llorando.

Dicen que la selva tiene

color de sangre y rencor.

Pero mi amor aún no viene

a bailar conmigo el rock.

A Vietnam se fue mi amor.

Ye, ye, ye...

Y se ha pasado al Vietcong.

El empleo del estribillo de una canción como «La chica ye-ye», obra del chileno Luis Aguilé, aunque fue popularizada por Conchita Velasco, y que había sido «canción del verano» del año anterior, contrasta con el tono clásico del título y dota al texto de un sentido paródico que da un giro radical al tratamiento elevado que venía siendo habitual y era esperable en un asunto de tanta gravedad. La ironía y la burla degradan la tragicidad de la escena. La muchacha que espera solo tiene en la cabeza el amor y el rock, intereses propios de la juventud de la época, también del chico que se fue a Vietnam, quien sin embargo ha acabado allí harto de «sangre y rencor» y ha desertado para unirse al movimiento guerrillero. El verso final cierra con sorpresa y brillantez la parodia, que acaba siendo más eficaz que un vehemente alegato pacifista.

Entre 1966 y 1967 están fechados en Madrid y París los poemas del libro Llamarme Juansintierra, del jerezano Carlos Álvarez (1933) -otro poeta comunista que sufrió por ello muchos años de cárcel durante la dictadura franquista-, entre ellos «Juansintierra ni tiempo», donde equipara Vietnam a otros grandes ejemplos de la ignominia genocida:

...Cuando pasan

el Danubio y el Vístula risueños

por Auschwitz y Mauthaussen, cuando ponen

su nota blanca en el azul sin nubes

del Vietnam o Hiroshima los albatros (Álvarez 1978, 129).

De la misma ideología era Gabriel Celaya (1911-1991), que en 1967 publicó «Noticias de la última guerra», un duro alegato contra los intereses capitalistas de la guerra, en su libro Lo que faltaba:

Matar es un negocio.

Cuando en Vietnam parece posible un armisticio, hay baja en Wall Street, y se arruinan los que tienen aún algo que perder; 
mas, falsa alarma, todo vuelve a subir y subir:

las acciones y los precios

(no los salarios, es claro, que amenazan inflación).

Matar, eso es lo bueno.

Lo que lleva la vida al cielo.

lo que extirpa el peligro de los amarillos,

$[\ldots]$

¡Es el honor de la patria, claro está! (Celaya 2002, 504).

El grupo responsable de Claraboya, posiblemente la principal revista poética de ese tiempo (Lanz 2005), prestó atención a lo largo de 1967 a la guerra en coherencia con su propuesta de una poesía dialéctica frente a la tendencia culturalista que se apreciaba ya desde los inicios en una notable serie de los poetas más jóvenes. En el número 13 de enero-febrero Agustín Delgado (1941-2012) incluye «Paz, 67», «Oh, el pasado» y «Calor»; y Luis Mateo Díez (1942), en su vertiente de poeta luego relegada por la de novelista, «Canciones», donde reaparece la ironía y el ritmo de canción popular para denunciar la escalada de la industria militar:

Me gustan los cañones que hacen buen fuego...

Mi fábrica produce

calibres nuevos.

Mi fábrica es hermosa

con tanto acero.

Mi fábrica es un horno de dividendos.

Me gustan los cañones que hacen buen fuego...

Cuántas muertes producen, cuanto jaleo allá por el Vietnam.

Estoy contento.

El Pentágono quiere seguir mi juego y yo soy muy feliz entre el acero.

Me gustan los cañones que hacen buen fuego.

Muy distinto será el tono del libro Baladas para una guerra fría de José Antonio Llamas (1941) que ocupa monográficamente el número de la revista 
correspondiente a noviembre-diciembre de ese año, cuyos poemas se insertan en la tradición de la poesía antibelicista, denuncian los estragos de la guerra, la pérdida de vidas inocentes y demandan la consecución de una paz basada en la justicia y la no injerencia internacional. Es este contexto el que explica los poemas antibelicistas de la segunda sección del libro de Luis Mateo Díez Señales de humo, publicado en 1972.

En esa misma línea se sitúa Ángela Figuera Aymerich (1902-1984), contemporánea de Rafael Alberti y Luis Cernuda, aunque no publicó sus primeros libros hasta finales de los años cuarenta (Mujer de barro, 1948, Soria pura, 1949). De ideología socialista, la suya es una poesía enraizada en los problemas de la realidad, donde la denuncia de la guerra ocupa un lugar primerísimo. Su mirada ofrece una gran empatía con las víctimas. La serie «Vietnam (primeros planos)», escrita en Avilés entre 1967 y1968, está compuesta por cinco poemas: «Los viejos», «Los niños», «Las madres», «El arroz» y «La selva» (Figuera 1986, 337-341). En ellos expresa el patetismo que desprenden numerosas fotografías de prensa y el heroísmo implícito en la resistencia de un pueblo a la invasión extranjera («Vemos al yanqui con su presa: / un viejecito andrajoso / con los ojos vendados y las manos atadas / a la espalda [...] El yanqui tiene miedo. Teme a esos viejos. Sabe / que tras los míseros harapos / en el hundido pecho ennegrecido, / se oculta un recio corazón gigante / con espoleta de odio inextinguible; un explosivo extraño y peligroso»)); y denuncia la masacre de víctimas infantiles y la insensibilidad del soldado norteamericano «Mirad y ved los niños aplastados, / acuchillados, rotos, / perforados, roídos / por el napalm [...] (El yanqui escribe a la familia / y manda besos a los pequeñines)», el sufrimiento de las madres y la programada devastación de los campos de cultivo («y en el Vietnam, matar es la consigna. / Matemos el arroz. Hagamos hambre. // Llegan aves tronadoras / y el arrozal sagrado es destruido.») o de la selva, cómplice en la estrategia guerrillera de la insurgencia («La selva es vietnamita; / es vietcong, antiusa. / Hay que matar la selva [...] Todo agoniza, todo se disuelve / en humo y brasa; en polvo dolorido. // Porque en Vietnam, matar es la consigna»).

De 1967 es también el poema de Carlos Sahagún (1938) «Meditación», luego incluidos en su libro Estar contigo (1973). Es muy interesante comprobar cómo la alabanza del guerrillero vietnamita sirve para el contraste con la vergüenza por la inacción en la España de la dictadura franquista. Frente a la valentía con que allí se arrostra el peligro diariamente, se resalta la cobardía de aquí «ante la vida cotidiana: el café, los saludos, / las inauguraciones, los afectos. / Y nos sentimos desplazados. Este lugar no es nuestro, / la vida alrededor es artificio, / premisa infiel de nuestros pensamientos [...] Mi corazón pelea en las selvas, muere / y renace sin tregua cada día» (Sahagún 1973, 7879). Esa admiración por el combatiente del Vietcong, enjuto, mal armado, pero con la fe de quien lucha por un ideal definido, llegaría incluso a quien se proclamaban ideológicamente contrario, como el cordobés Juan Bernier (1911- 
1989), que en el poema «Hombre de Hanoi» confiesa: «Sin saber si razón tienes, hombre desnudo de Hanoi [...] ¡oh espécimen de hombre! / Yo que soy del bando contrario, acaso, / yo que odio los tiranos verdosos y los rojos, / rindo mi mente a ti, de historias y recuerdos, / mi memoria de caídos y de héroes; / si tienes la razón, si no la tienes / y he de admirarte como caña, como junco, / como serpiente machacada que revive, / como hombre en un pasmo insólito / de voluntad descalza» (Bernier 1977, 92).

En ese 1967 publica sus primeros textos el poeta salamantino Aníbal Núñez (1944-1987). Se trata de una edición no venal en colaboración con Ángel Sánchez de título 29 poemas, catorce de los cuales son obra de Núñez. De ellos, cuatro de ellos se refieren al Vietnam: «Carta a Merry Fine (U.S.A.)», «Érase que se era», «Canción» y «Te caes de dulce amor sobre tu sueño azul» (Núñez 1995, 36-40), en los que denuncia el secuestro de los sueños de la juventud norteamericana por unos intereses por completo ajenos a sus deseos. En 1972 publicaría Aníbal Núñez Fábulas domésticas, que incluye el poema «La distinción de un cigarrillo largo», donde denuncia con dureza la maquinaria propagandística norteamericana:

\author{
donde impera el buen gusto \\ internacionalmente \\ encender cien milímetros de fresco \\ sabor joven regar \\ la jungla de napalm es un detalle \\ de personalidad tanto en la calle \\ como en torno a la mesa de negocios \\ en una plácida velada \\ o en el regazo cálido de un b-52 (Ibíd., 59).
}

Por fin, también de 1967 es un poema singular de no poca importancia en la evolución de la poesía española, donde la presencia de la Guerra de Vietnam es muy clara. Me refiero a «Arte poética» de Manuel Vázquez Montalbán (1939), incluido en su libro Una educación sentimental, cuya intención programática es evidente al señalar hitos de un mapa lírico propio, tanto por las adhesiones como por los rechazos estéticos y vitales que serán bastante compartidos por los poetas de esa promoción emergente. En los primeros versos de esta sucesión aparentemente incoherente de referencias hay una acotación muy similar a las que ya vimos en Félix Grande: «chorretes de sangre en las primeras / páginas...»; y pocos después se evoca la guerra mencionando a quien era Secretario de Estado de los EE.UU.: «y en el sudeste asiático / la guerra McNamara cruza el río», que parece tan cercana como la noticia que sigue: «se ahorca a un inocente en esta casa / aquí / junto a las tumbas de pioneros / del renacer textil de las vetes / i fils». Es decir: importa tanto la guerra injusta que se desarrolla a miles de kilómetros como la represión de la dictadura franquista, que tenía la horca como uno de sus métodos de ejecución de penas capita- 
les, vigente aún entonces. Y en realidad estaban conectadas, pues el antinorteamericanismo de la izquierda española tenía su origen en el apoyo decisivo de EE.UU. para la consolidación del régimen de Franco en la posguerra. Además, todavía estaba próximo el episodio de la colisión de dos aviones militares norteamericanos y la caída de cuatro bombas atómicas en la provincia de Almería en enero de 1966, que originó en abril siguiente una manifestación ante la embajada de Estados Unidos en Madrid.

1968 fue un año determinante para el desarrollo de la guerra, como vimos, por el aumento de bajas en ambos ejércitos, pero sobre todo de víctimas civiles, lo que se traduce en un incremento de poemas alusivos, algunos publicados entonces, otros en libros posteriores, muy cercanos a los hechos, en ocasiones, como se ha visto, motivados por la lectura de los periódicos, lo que explica que prime el contenido sobre su acabado formal. A los ya mencionados de Alberti, León Felipe, Guillén y Ángela Figuera hay que añadir el del gallego Celso Emilio Ferreiro (1912-1979) «Digo Viet Nam y basta» en edición bilingüe, que enumera sustantivos asociados a la espantosa situación que sufría ese país: «Digo niños de napalm, / terror de noche y selva, / hedor de ciudad y cloaca [...] Digo plutonio, pentágono, / estiércol bursátil, palanca, / Presidente, zarpa, / lluvia, amargura, baba [...] Digo petróleo, hierro, / mineral, trampa, / lobo, caimán, polaris, culebra, / miseria, diplomacia. Digo devastación que U. S. A., usa. [...] Para abarcar la vergüenza del mundo, / digo Viet Nam y basta» (Ferreiro 1975, 366-369).

En Cataluña el asunto despertó un interés semejante, potenciado por la oposición a la dictadura de Franco, represora de las libertades ciudadanas y de su identidad cultural específica, que se equiparaba a la acción imperialista de EE.UU. en Extremo Oriente. Quien probablemente fuera su autor más señalado, Salvador Espriu, dedicó un poema «A les víctimes d'un innecessari i estupidíssim sofriment» titulado «Viet-Nam», donde confiesa malvivir «en un país / que no es lliure, / canssadissim, cruel, / corrumput, molt covard. / Em toca de malviure / en un país indigne, / peró la resta del món / no és pas millor». Y censura el desprecio de los «senyors del poder» y la «Vergonya $i$ deshonor / de tots els pobles» (Espriu 1985, 84-85), que consentían la devastación de Vietnam. También en catalán Gabriel Ferrater (1922-1972) había utilizado el sarcasmo para denunciar la crueldad norteamericana en la guerra en su poema «Cançó del gosar poder» («Canción del atreverse a poder»):

No gosis, no poder perdre batalles.

Però tampoc no et cal guanyar-les totes.

Si tens napalm per sembrar camps del Nord, gosa poder perdre guerres de Sur 5 .

\footnotetext{
5 «No te atrevas, no, a poder perder batallas. / Pero tampoco hace falta ganarlas todas. / Si tienes napalm con que sembrar campos del Norte, atrévete a poder perder guerras del Sur» (Ferrater 1979, 252-253).
} 
En los primeros días de enero de ese 1968 se celebró en La Habana un Congreso Cultural organizado por el gobierno de Cuba con el objetivo aparente de buscar soluciones a los problemas de los países subdesarrollados. En realidad, el gobierno cubano, acosado por el bloqueo económico y político de EE.UU., pretendía, en palabras de Carlos Barral, «la afirmación internacional de la revolución con el apoyo universal de los intelectuales de izquierdas, es decir, de la mayoría de la clase intelectual de Europa y América» (Barral 1988, 133). Entre los poetas españoles asistentes se contaron José Manuel Caballero Bonald (1926), José Ángel Valente (1929-2000) y Alfonso Sastre (1926) que, como Blas de Otero, residente entonces en la isla, pudieron conocer de primera mano no solo los logros revolucionarios de Fidel Castro, sino también la versión norvietnamita de la guerra, pues la delegación de la República de Vietnam fue la invitada de honor al Congreso y sus miembros tuvieron un protagonismo especial. Cuba, que había declarado 1967 «Año del Vietnam heroico», era estrecha aliada suya al compartir a los EE.UU. como enemigo. Los cuatro escribieron textos sobre el asunto que nos ocupa.

Caballero Bonald fechó en La Habana un poema titulado inicialmente «Idioma del héroe», publicado un año después en la revista de la cubana Casa de las Américas, que hoy conocemos como «Bich Som explica que está vivo» ${ }^{6}$. En él se refiere a una conferencia del diplomático Hoang Bich Son (1924-2000), representante de Vietnam del Norte en ese Congreso, a la que asistió en esos días:

No has olvidado los aceros del héroe, su impávida y reverenciosa manera de explicar, parpadeando

$[\ldots]$

Y luego ya, de pronto, fue la ira:

juntos y pavorosos te mostraron

los mandamientos del terror, los ejemplos aullando como lobos, aquella interminable agonía de agujas de lazy-dogs despedazando a un pueblo, las imágenes no ya en abreviaturas ni en emblemas sino en gritos, mutilaciones, bombardeos, torturas: medio millón de guerrilleros muertos, una resucitable multiplicación de muertos enseñando a sus muertos a recobrar la vida, adiestrándolos juntos en el odio para prevalecer del odio, y allí mismo, delante de tu alma, todavía

${ }^{6}$ Ese texto fue publicado en la revista Casa (52, marzo-abril 1969, pp. 98-99 con el título «Idioma del héroe» e incluido con el título «Acero del héroe» en la primera recopilación de su poesía Vivir para contarlo. Después, el poema adoptaría el título «Bich Som explica que está vivo» en su libro Descrédito del héroe (1977), aunque sería reubicado en Pliegos de cordel en la reordenación de su poesía completa Somos el tiempo que nos queda (2004). Cfr. (Caballero Bonald 2015, 343-344). 
delante de tu alma, al tiempo que Bich Son cotejaba las pruebas del triunfo, tú aprendías la horrenda asignatura: las bárbaras industrias del napalm y los tóxicos químicos y la gasolina gelatinada y el fósforo blanco y toda la espantosa cortina de exterminio que obstinadamente tratabas de entreabrir, para asomarte más allá de tu ira y comprobar, no sin vergüenza, que eras sólo un testigo.

José Ángel Valente, que en 1966 había publicado la traducción de dos poemas sobre la guerra del vietnamita Che-Lan-Vien (Valente 2014, 867-870), trata el tema en el poema «Las legiones romanas», del libro Breve son (1968), donde equipara el imperialismo yanqui al de Roma en su voluntad de dominio del mundo y proclama la inutilidad del empeño:

Las legiones romanas aún se baten

desde hace dos mil años

en los pantanos y los arrozales

$[\ldots]$

El enemigo ha sido aniquilado

cuatro mil veces en tantos dos mil años

y las legiones aún se baten

contra los mismos muertos (Valente 2014, 261).

Por su parte Alfonso Sastre, militante comunista, escribió al menos tres poemas, que se publicarían en libro diez años después (Sastre 1978a, 142-146): «Vietnam, Vietnam» describe una pesadilla en la que el poeta es prisionero en la selva vietnamita; $\mathrm{y}$ «Ho Chi Minh (Homenaje)» es una glosa en redondillas de los nueve versos de un poema de Nicolás Guillén al líder norvietnamita, que lleva como lema. En «Te veo Vietnam», fechado en 1968-1969, Sastre cuenta la historia de la guerra con lenguaje infantil en una serie de pareados consonantes al modo de los antiguos pliegos de cordel:

Caen las bombas a millones

encima de poblaciones

$[\ldots]$

Las casas quedan deshechas

y quemadas las cosechas.

$[\ldots]$

Son valientes y certeros

los soldados guerrilleros

$[\ldots]$

Napalm y fósforo arrojan.

Queman todo lo que mojan

(Sastre 1978b, 89-96). 
En 1968 la guerra estaba en su apogeo y también su actualidad poética. Durante ese Congreso Cultural de La Habana celebrado en enero surgió la idea de preparar una antología poética con textos contra la guerra de Vietnam, auspiciada por el Partido Comunista, similar a la que en 1962 se publicó en apoyo de la Revolución cubana, España canta a Cuba7. No olvidemos que en la estrategia de la lucha antifranquista se concedía a la poesía un lugar significativo, como evidencia la conmemoración del vigésimo aniversario de la muerte de Antonio Machado en Collioure y la creación de la colección Colliure por los poetas del grupo de Barcelona Carlos Barral, José Agustín Goytisolo y Jaime Gil de Biedma. Se atribuiría la idea Gabriel Celaya, pero en nombre del Partido fue Genoveva Forest quien, a su regreso a España desde La Habana, encargó la recopilación de poemas a su amiga la poeta Angelina Gatell, militante anti-franquista que tenía experiencia como antóloga porque ayudaba en una de poesía femenina a Carmen Conde (1971). Recopilados los textos y dibujos, se intentó publicar en España con el título Con Vietnam, para lo que se buscó la editorial Ciencia Nueva, cuyos socios eran miembros o estaban muy próximos al PCE, y se presentó a la censura en septiembre de 1968. El endurecimiento del Régimen en enero de 1969 con la declaración del estado de excepción en enero de 1969 se tradujo en la prohibición de la antología, cuyo original quedó olvidado en el archivo de la censura, de donde fue recuperada casi medio siglo más tarde (Neira 2016).

En la introducción de la edición reciente de Con Vietnam se explica con detalle el proceso de elaboración y el trámite administrativo de la censura gubernativa, por lo que remitimos a esas páginas. Sí conviene recapitular que, además de los textos entonces publicados, y otros inéditos ya mencionados (los de León Felipe, Alberti, Aleixandre, Diego, Caballero Bonald, Salvador Espriu, Celso Emilio Ferreiro, Celaya, Valente, Otero, Caballero Bonald, Ángela Figuera, etc.), Angelina Gatell reunió muchos otros, escritos para la ocasión; algunos de los cuales después fueron incluidos por sus autores en libro, pero otros permanecieron olvidados hasta su reciente rescate, como el de Ángel González, el de José Agustín Goytisolo o el de Rafael Morales. Se trata de obras de poetas muy variados desde perspectivas diferentes: geografía, lengua, ideología y tendencia estética. Es notable la presencia de poetas en catalán (Joan Colomines, Josefa Contijoch, Salvador Espriu, Joaquím Horta, Josep Llompart, Francesc Parcerisas, Marta Pessarrodona, Pere Quart y Francesc

${ }^{7}$ España canta a Cuba, París, Ruedo Ibérico, 1962. Incluye poemas, entre otros, de Blas de Otero, Rafael Alberti, Carlos Álvarez, Julián Marcos, Joaquín Marco, Gabino Alejandro Carriedo, Ángel Crespo, Lauro Olmo, Aquilino Duque, Jesús López Pacheco, Ángel González, Carlos Barral, José Agustín Goytisolo, Leopoldo de Luis, José Ángel Valente, Jaime Gil de Biedma, Juan Rejano, Pere Quart, Ángela Figuera Aymerich y Gabriel Celaya; e ilustraciones de José Ortega, Juan Haro, Ricardo Zamorano, Eduardo Arroyo, Antonio Saura, Manuel Millares, Francesc Todó y Francisco Mateos. 
Vallverdú), en gallego (Lois Diéguez, Celso Emilio Ferreiro, Xose Luis Franco Grande, Manuel María, Uxío Novoneyra, Ramón Regueira) y en vasco (Gabriel Aresti). También sobresale la participación de autoras, en número excepcional en antologías generales y seguramente debida a que la antóloga fue una mujer. Encontramos a Aurora de Albornoz, Elena Andrés, María Luisa Chicote, Josefa Contijoch, Sabina de la Cruz, Ángela Figuera, María de los Reyes Fuentes, Gloria Fuertes, Angelina Gatell, Cristina Lacasa, María Elvira Lacaci, Concha de Marco, Marta Pessarrodona y Pura Vázquez. Y si algunos no enviaron poemas, dejaron constancia de su simpatía con el proyecto, como Buero Vallejo, Carlos Bousoño, José Luis Cano, José Luis Prado Nogueira, María Beneyto, Vicente Gaos, cuyas cartas pueden verse en la edición de la antología.

No menos notable es la diversidad formal que presentan, desde la clásica estructura de los sonetos (Leopoldo de Luis, Rafael Morales) y las liras (Gerardo Diego) o la popular de las coplas (Miguel Fernández) a la libertad versal de la mayoría y, en el extremo, la experimentación visual, tan novedosa entonces, de Uxío Novoneyra y de Josefa Contijoch. También la perspectiva con que los textos encaran el tema de la guerra es muy diversa, desde la religiosidad del poema navideño de Victoriano Crémer y las oraciones de María Elvira Lacaci y de Pura Vázquez, a la empatía por el sufrimiento personal de los más indefensos, niños y ancianos, de Ángela Figuera Aymerich, Gloria Fuertes o José Gerardo Ladrón de Guevara, y el planteamiento abiertamente político de la mayoría. Se trata de una antología integradora que acoge a poetas tan diferentes en todos los sentidos como los hermanos Murciano y Carlos Álvarez o José Luis Gallego, que sufrieron largos años de cárcel por su actividad antifranquista.

La prohibición de la antología no paró, sin embargo, la creación de poemas pro-vietnamitas. En ese año de 1969 escribió Leopoldo de Luis (1917-2005) su soneto «Hazañas humanas», que se interroga sobre la esquizofrenia de un país, EE.UU., capaz de anunciar al mundo el mismo día -20 de noviembre de 1969un avance científico y técnico de la magnitud del alunizaje de la nave Apolo XII y la matanza de My Lai, ocurrida en marzo del año anterior: «Es esta misma mano, esta paloma / esta rama de luz, esta hoja herida / por la ráfaga hermosa de la vida / la que el prodigio y el ultraje toma» (Luis 2003, 478). Como ya se dijo, el impacto de esa matanza en todo el mundo fue brutal. Aurora de Albornoz (1926-1990) se refiere a ella en su poema «Niños del mundo»: «Estrellas a las cuatro / esquinas de los vientos / están fijos tus ojos, / tus congelados ojos, / tus cien ojos, / tus miles amarillos / de ojos en / MY LAI» (Albornoz 1983, 38). De esa misma época debe de ser el poema «Shadows», de Extraña fruta y otros poemas, de Pedro Gimferrer (1945), que entre los elementos del imaginario bélico menciona «empapado de lluvia sangre Napalm lianas en Hanoi» (Gimferrer 1979, 81). Gimferrer me contó que por entonces escribió un poema específicamente dedicado a la guerra donde se mencionaba al Vietcong, que enseñó a Vicente Aleixandre y a este no acabó de gustarle. Si recordamos que el poeta de 
Velingtonia eliminó la mención a Vietnam de su poema en Diálogos del conocimiento, podemos suponer que considerara en exceso vinculado a los hechos el de Gimferrer, y de ahí su desaprobación. Por respeto al criterio de su maestro, Pere Gimferrer ha dejado ese texto sin publicar.

El malagueño José Infante (1946) se inicia en la poesía en ese año 1969. $\mathrm{Su}$ poema «Los muertos» es un crudo alegato contra la guerra con tintes visionarios:

....al sonar el quinto gong todos se quedaron parados.

Eran los asesinos subidos a los tanques

proporcionados por el general Wesmoreland (Infante 1990, 133).

En el libro Uranio 2000. Poemas del caos dedica Infante un poema, «Las musas destrozadas» a tres actrices de trágico final: Marylin Monroe, Françoise Dorleac y Sharon Tate; y en la parte dedicada a esta, víctima de Charles Manson y su secta en agosto de 1969, relaciona la violencia asesina y los efectos de las drogas que sufría la juventud norteamericana con la situación en Vietnam:

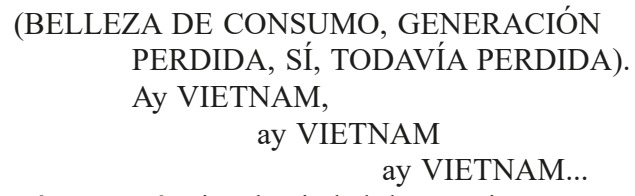

Tú no querías ir a la ciudad de Hanoi,

rubia, rebelde doncella, verde doncella,

tú no querías ir a Saigón

[...]

vengativa, sangrienta, violenta América

ay América asesina

numerosamente asesina

terriblemente asesina

veraniegamente asesina...

América).

-ALLEN GINSBERG SE DROGA CON OJOS DE

VIETNAMITAS RUBIOS-

Ay América, (Ibíd., 151-153).

Aún en el poema «El silbo de los aires amorosos» de su libro inédito entonces El mar es mi tipo se refiere Infante a la guerra del Vietnam como episodio decisivo en la formación emocional de su generación:

\footnotetext{
que nos estaban preparando para el odio, la guerra

del Viet-Nam fue entonces cuando cobró significado

y el hambre y la mancillada paloma de la paz,

que nunca antes ni mar, ni amor, ni tarde de domingo,

habíamos distinguido en el correr de los veranos (Ibíd., 199).
} 
En 1970 la antología promocional de Castellet Nueve novísimos poetas españoles incluía tres textos con alusiones a la guerra de Vietnam: el de Vázquez Montalbán ya mencionado; el de Antonio Martínez Sarrión (1939) «La Grande Guerre (magritte)» («qué quedará de esta larga molienda / de esta increíble fiesta del napalm», Martínez Sarrión 1981, 111); y el de José María Álvarez (1942) «Aquí y en todas partes hay que acorralar a la bestia loca del uso»: «G. I. Dont'go To Vietnam» (Castellet 1970, 115). Pero en los primeros años de esa década disminuyeron mucho las referencias poéticas.

En el caso de Blas de Otero, aparte de algunas menciones poco significativas, la guerra de Vietnam reaparece dos años después en el poema «No me moverán», del 30 de septiembre de 1970, y en «Los apolíneos», del 5 de febrero de 1971, dedicado a los norteamericanos:

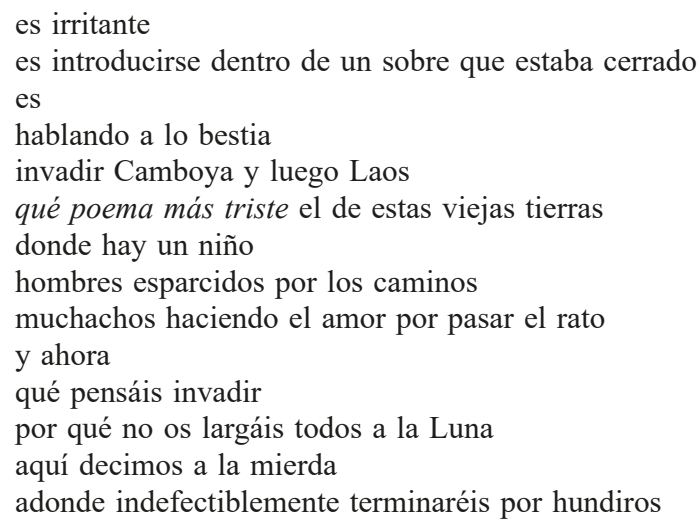

Aún dos años más tarde, el 5 de junio de 1973, en «Ni Vietnam» el poeta concentra en esa carencia el símbolo de la felicidad:

hasta la cintura del más pretencioso rascacielos (Otero 2013, 922-923).

y sonreí con esfuerzo

y el mundo no tenía ni Vietnam ni planchas ateridas

maravillosa mañana

para añorarla estando en el sanatorio (Ibíd., 927).

Y es asunto frecuente en sus escasas entrevistas (Rico 1970; Suñén 1976).

En 1973 encontramos la queja del almeriense Julio Alfredo Egea (1926) «Cristo sangra en el Vietnam» en su «Carta a Pablo VI» (Egea 2010, 528); y, lógicamente, el final de la Guerra determinó su casi desaparición, aunque aún pueden encontrarse referencias posteriores a 1975 de autores muy diversos en edad y estética. La poeta uruguaya Cristina Peri Rossi (1941), conocida como activista antinorteamericana y exiliada política en España desde 1972, cronológicamente afín a los llamados «novísimos», incluyó en su primer libro escri- 
to en Barcelona, Diáspora (1976), el poema «Antes del cese el fuego» que plantea el diferente tratamiento otorgado a los soldados de uno y otro bando con una fuerte carga irónica:

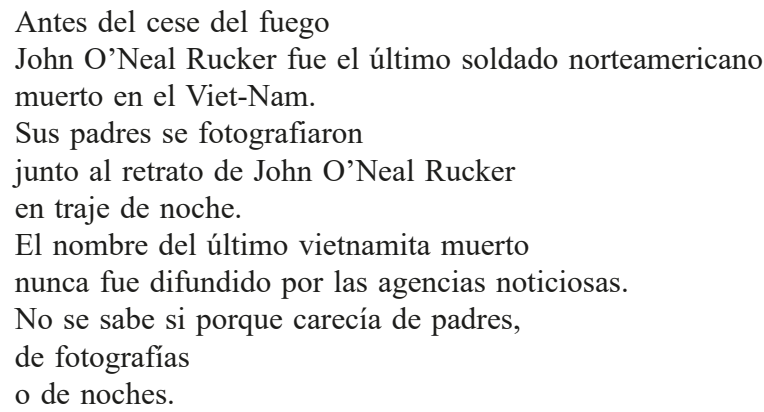

El sacerdote y poeta postista Carlos de la Rica (1929-1997) escribe en «Ícaro»: «Cuando / oigo el grito prolongado / del animal herido / bella estrella la de Hanoi / bellos campos, casas, chozas y / ¡afilar las espadas! / Le han ordenado lanzar sobre la garganta un plato / para que se haga añicos / El viejo guante de Ho Chi Minh / escurría / sobre las losas / escurría sobre las hojas» (Rica 1993). Y Luis Alberto de Cuenca (1950) incluye en Scolia el poema «The Gateway»: «Recoge tu equipaje. / Aprisa, ven. / Compiten en la selva la serpiente y el águila. / Los héroes envejecen en los museos» (Cuenca 1990, 65).

Leopoldo María Panero (1948-2014), incluido en Nueve novísimos..., publicaría más tarde su contribución al «género». En la sección «Páginas de poesía política» de su libro El último hombre (1984) hallamos dos poemas: «Soldado herido en Vietnam» y «Sueño de una noche de verano». En el primero es la voz del soldado norteamericano la que habla: «La muerte vació mi ser, dejó mis ojos / tan blandos y sexuales como selva [...] El avión me esperaba como una amenaza: / a medida que el terror se alejaba / vi la nave del sentido hundirse entre mis ojos. / En esta habitación de Windham Street / soy sólo un disparo entre los juncos» (Panero 1984, 16). El segundo se refiere al enemigo vietnamita en un poema de fuerte contenido sexual: «Los hombres del viet son tan hermosos cuando mueren. / El agua del río, lamiendo sus piernas, / hacía más sexual / su ruina. / Luego vinieron las Grandes Lluvias buscando / la vagina hambrienta de la selva, y todo lo borraron» (ibíd., 18).

Corrida la década del 70 casi todos los poetas españoles dejarían atrás el asunto en su obra, pues las conversaciones diplomáticas auguraban que tarde o temprano esa guerra terminaría con el abandono norteamericano de Vietnam del Sur en 1976. Pero el corpus expuesto, que no pretende ser exhaustivo, demuestra que, en un periodo decisivo de la historia de España, el de las grandes manifestaciones de la lucha antifranquista, la de Vietnam fue sentida como una guerra propia por los poetas españoles, hombres y mujeres, de todas las 
edades, convicciones ideológicas y direcciones estéticas, que en textos de notable variedad formal elevaron su protesta contra la que consideraron una guerra injusta, en un ejercicio colectivo de civismo nunca después repetido.

\section{BIBLIOGRAFÍA}

AA.VV. 1969. Poemas al Che. La Habana: Instituto Cubano del Libro.

Alberti, Rafael. 1966. El poeta en la calle. Poesía civil. Paris: Éditions de la Librairie du Globe.

Alberti, Rafael. 1988. Poesías completas. Ed. de Luis García Montero. 3 vols. Madrid: Aguilar.

Alberti, Rafael. 2004. Poesía IV. Ed. de José María Balcells. Barcelona: Seix Barral.

Albornoz, Aurora de. 1983. Palabras reunidas. Madrid: Ayuso.

Aleixandre, Vicente. 1974. Diálogos del conocimiento. Barcelona: Plaza y Janés.

Álvarez, Carlos. 1978. Antología. Madrid: Editora Nacional.

Barnatán, Marcos Ricardo. 1984. El oráculo invocado. Poesía 1965-1983. Madrid: Visor.

Barral, Carlos. 1988. Cuando las horas veloces. Barcelona: Tusquets.

Bernier, Juan. 1977. Poesía en seis tiempos. Madrid: Editora Nacional.

Caballero Bonald, José Manuel. 2015. Descrédito del héroe. Manual de infractores. Ed. de Julio Neira. Madrid: Cátedra.

Castellet, José María. 1970. Nueve novísimos poetas españoles. Barcelona: Barral.

Celaya, Gabriel. 2002. Poesías completas II. Ed. de José Ángel Ascunce, Antonio Chicharro y Jesús María Lasagabaster. Madrid: Visor.

Conde, Carmen. 1971. Poesía femenina española (1950-1960). Barcelona: Bruguera.

Cuenca, Luis Alberto de. 1990. Poesía, 1970-1989. Sevilla: Renacimiento.

Diego, Gerardo. 1966. Odas morales. Málaga: Publicaciones de la Librería Anticuaria El Guadalhorce.

Egea, Julio Alfredo. 2010. Poesía completa. Almería: Instituto de Estudios Almerienses.

Espriu, Salvador. 1985. Obres completes. Anys d'aprenentatge I. Poesía. Ed. de Francesc Vallverdú. Barcelona: Edicions 62.

Ferrater, Gabriel. 1979. Mujeres y dias. Barcelona: Seix Barral.

Ferreiro, Celso Emilio. 1975. Obra poética completa. Madrid: Akal.

Figuera, Ángela. 1986. Obras completas. Ed. de Roberta Quance. Madrid: Hiperión.

Fuertes, Gloria. 1968. Poeta de guardia. Barcelona: Ciencia Nueva.

García, Miguel Ángel. 2012. La literatura y sus demonios. Leer la poesía social. Barcelona: Castalia.

Gimferrer, Pere. 1979. Poemas 1963-1969. Madrid: Visor.

Goytisolo, José Agustín. 2009. Algo sucede, Poesía completa. Ed. de Carme Riera y Ramón García Mateos. Barcelona: Lumen.

Grande, Félix. 2011. Biografía (1958-2010). Barcelona: Galaxia Gutenberg.

Guillén, Jorge. 1973. Y otros poemas. Buenos Aires: Muchnik.

Infante, José. 1990. Poesía 1969-1989. Málaga: Ayuntamiento.

Iravedra, Araceli y Leopoldo Sánchez Torre, eds. 2010. Compromisos y palabras bajo el franquismo. Recordando a B las de Otero (1979-2009). Sevilla: Renacimiento.

Lanz, Juan José. 2005. La revista "Claraboya» (1963-1968): un episodio fundamental en la renovación poética de los años sesenta. Madrid: UNED.

Lanz, Juan José. 2008. Alas de cadenas. Estudios sobre Blas de Otero. Sevilla: Renacimiento. 
Lanz, Juan José. 2009. Las palabras gastadas. Poesía y poetas del medio siglo. Sevilla: Renacimiento.

Lanz, Juan José. 2011. Nuevos y novísimos poetas en la estela del 68. Sevilla: Renacimiento. Luis, Leopoldo de. 2003. Poesías Completas, I. Madrid: Visor.

Martínez Sarrión, Antonio. 1981. El centro inaccesible. Madrid: Hiperión.

Neira, Julio. 2001. «Rafael Alberti y Gerardo Diego: confluencias y divergencia en la poesía española (1925-1936)». Boletín de la Biblioteca de Menéndez Pelayo 77: 35-62.

Neira, Julio, ed. 2016. Angelina Gatell, ant., Con Vietnam. Madrid: Visor.

Núñez, Aníbal. 1995. Obra poética I. Ed. de Fernando R. de la Flor y Esteban Pujals Gesalí. Madrid: Hiperión.

Otero, Blas de. 2013. Obra completa. Ed. de Sabina de la Cruz y Mario Hernández. Barcelona: Galaxia Gutenberg.

Panero, Leopoldo María. 1984. El último hombre. Madrid: Ediciones Libertarias.

Pardellas Velay, Rosamna. 2009. El arte como obsesión: la obra poética de Aníbal Núñez en el contexto de la poesía española de los años 70 y 80 . Madrid: Verbum.

Payeras Grau, María, ed. 2016. Fuera de foco. Aproximaciones a la diversidad poética del medio siglo. Madrid: Visor.

Rica, Carlos de la. 1993. Poemas junto a un pueblo, Poesía 1959-1989. Barcelona: Anthropos.

Rico, Eduardo G. 1970. «Blas de Otero: Historias fingidas y verdaderas». Triunfo 437, 17 octubre: 38 .

Sahagún, Carlos. 1973. Estar contigo. León: Diputación provincial.

Sastre, Alfonso. 1978a. El español al alcance de todos. Madrid: Semsemará Chororó.

Sastre, Alfonso. 1978b. T.B.O. Bilbao: Zero.

Suñén, Luis. 1976. «Blas de Otero con los ojos abiertos». Reseña 91, enero: 17-19.

Ullán, José Miguel. 1966. «Lamentaciones de una muchacha yanqui a eso de la medianoche». Claraboya 11: 16.

Valente, José Ángel. 2014. Poesía completa. Ed. de Andrés Sánchez Robayna. Barcelona: Galaxia Gutenberg.

Fecha de recepción: 11 de diciembre de 2017.

Fecha de aceptación: 31 de enero de 2018. 